\title{
Spatial direction and grammatical form of instructions affect the solution of spatial problems
}

\author{
LAUREN JAY HARRIS \\ Michigan State University, East Lansing, Michigan 48824
}

\begin{abstract}
One hundred and forty-eight undergraduate women were orally instructed to repeatedly and quickly draw circles in spatial relation to squares printed on sheets of paper. On each trial, the instructions required the circle to be drawn either above, below, to the right of, or to the left of the square. The instructions were expressed so that the circle was either the logical subject (e.g., "circle above square") or the logical object (e.g., "square below circle") of the statement. Each subject received all experimental conditions for a total of 24 separate drawings per subject. Analysis of variance of the total number of errors disclosed significant effects of all experimental variables. Performance was significantly more accurate when the circle was the logical subject, when the orientations were "above" and "right of" rather than "below" and "left of," and for the vertical dimension. The results are discussed in terms of current theories on "asymmetries" in information processing.
\end{abstract}

Huttenlocher (Huttenlocher \& Strauss, 1968) has suggested that comprehension of a sentence requires a correspondence between the form of a linguistic expression and the situation it describes. In support of this view, she and Strauss present a simple demonstration with young children. A colored block (A) is placed in the center shelf of a five-shelf ladder. A second block (B) is placed beside the ladder, and the child is asked to put it in the ladder, making it correspond to a relational statement that indicates whether B should be above or below the fixed block A. The relation of the mobile block $B$ to the fixed block $A$ is described in two ways-where $B$ is to go on top, either " $B$ is on top of $A$ " or " $A$ is under $B$;" and where $B$ is to be underneath, either " $B$ is under $A$ " or " $A$ is on top of B." In the first of each of these pairs of statements, B, the mobile block, is the logical actor or subject. In the second of each pair of statements, the fixed block $A$ is the logical actor, and B is acted upon.

The children made significantly more errors and had longer latencies in the latter cases, where the mobile block B was the logical object of action in the sentence. Huttenlocher suggests that the children found it harder to place the mobile block under these circumstances because they had to carry out mental operations to create a correspondence between the mobile object B and the logical actor in the statement. This mental operation was to transform the experimenter's statement by exchanging subject and object and reversing the relational term.

This hypothesized account of the underlying process

Thanks are due to Catherine Best and Roy Pea for help in testing subjects and in tabulating scores, Ralph Cooper for designing and carrying out the analy sis of variance of the scores, and Gary Olson and Andrew Gilpin for their comments on an earlier version of this report that was presented at the Fourteenth Annual Meeting of the Psychonomic Society, November 2, 1973, St. Louis, Missouri. Address reprint requests to Lauren Jay Harris, Department of Psychology, Michigan State University, East Lansing, Michigan 48824. gains some support from the children's spontaneous comments. For instance, given a mobile green block and the statement, "The red block is on top of the green block," some children said, "Oh, you mean the green block goes under the red one."

This model is concerned primarily with the question of differences as a function of the position of the "mobile" object in the instruction. But it does not necessarily imply that within the same grammatical form condition, one spatial direction (under) would be more or less difficult to understand than another (over, on top of).

Such an "asymmetry" has been found. Clark and others (Clark \& Chase, 1972; Olson \& Laxar, 1973) have studied adults' reaction times in matching sentences describing a spatial relation between geometric forms to a visual display showing a spatial relation between the same forms. For example, the subject had to judge whether the sentence, "The circle is above the square," matched or failed to match a visual display in which the circle was below the square. It took significantly longer to verify sentences that included the spatial terms "below," "back," and "left" than sentences that included their opposite terms "above," "front," and "right."

Clark has proposed that these asymmetries are related to how people conceptualize space. His analysis of "conceptualized space" is based on both geometrical and biological considerations. So, asymmetries of the spatial terms above and below and front and back can be traced to physical asymmetries of the human body in the frontal and transverse planes. For example the "top" or "above" part of the body or, more specifically, the top-front part of the body is the side of action in the world. It is the part of the body on which the eyes are located, and from which the arms and hands naturally extend, and the side of both visual and physical social interaction. The baby's first objects he draws to himself 
are drawn to the front and upper part of his body (the eyes and mouth). For these structural reasons, "up" or "above" and "front" become the "normative" directions for human beings. It is harder to make the same argument in the case of the horizontal dimension. The right side of the body, externally, very nearly mirrors the left. Such asymmetry as exists is insignificant compared with asymmetries between the upper and lower and front and back parts. The critical factor instead may be use: most people being right-handed, the right side for them might constitute the normative side, and the right direction, the normative direction.

Clark has also suggested that the spatial terms "up," "above," "front," and "right" have different lexical properties from their opposites, akin to the different lexical properties on nonspatial polar opposites like long and short, and that the asymmetries in reaction time between above and below, front and back, and right and left reflect these different semantic statuses.

In the case of long and short, long can be used in both a nominal and a contrastive sense. That is, long means "of the dimension length" or it can mean "longer than average" (i.e., it can refer to comparisons between objects of different length). But short can be used only in the latter contrastive sense and never means merely length. Thus, while we can say, "The board is $10 \mathrm{ft}$ long," it is ungrammatical to say, "The board is $10 \mathrm{ft}$ short." In traditional linguistic terminology, "short" is called "marked" because it cannot be so used, but instead always implies a comparative scale. And "long" is "unmarked." Clark suggested that this kind of analysis is applicable to many of the spatial adjectives in English.

This line of reasoning fits well with the late Heinz Werner's organismic perceptual theory (Werner, 1961). Werner believed that the most important clue to the source of the major systems of spatial coordinates-above-below, left-right, as well as front-behind, is the body itself, with "objective space" evolving from this "primitive" (in the sense of fundamental) orientation. ${ }^{1}$

The dimensions left-right and above-below seem to differ from spatial-adjective terms like long-short in at least one important sense. They do not so clearly specify a physical dimension along which contrasts can be made. For instance, we can say farther or nearer for the dimension of distance, but there are not comparable terms "lefter," "righter," or "abover," "belower." And there is no common word that labels the left-right or above-below dimensions as distance labels the near-far dimension. Instead, we have to add the qualifier "farther," thus "farther above," "farther (to the) left of," and so forth. Or we can say that something is more or less directly above, below, left of, or right of something else. It is unclear whether we would or should take this usage to mean that object $A, 10 \mathrm{~m}$ to the left of object $\mathrm{C}$, is more left of object $\mathrm{C}$ than is another object that is only $5 \mathrm{~m}$ to the left of object C. Similarly, if object $A$ is $10 \mathrm{~m}$ above object $C$, it seems to be no more above $\mathrm{C}$ than is another object only $5 \mathrm{~m}$ above $\mathrm{C}$.

Why are the putatively semantically more complex "marked" terms harder to process than the "unmarked" terms? Clark suggests that to process information presented via the marked term, the subject first must transform that information into a representation that refers both to the underlying dimension (the "nominal" sense) and to the marker indicating that the transformation has to be applied. When this information has to be retrieved, the subject tends to lose the marker and retrieves the initially marked terms as their unmarked counterparts.

In the current study an attempt was made to combine assumptions about syntactic and semantic factors into a single study with adults. In previous studies with adults, perhaps because reaction time has been the main measure, the number of actual errors of judgment has been extremely low, and no consistent relation has been reported between frequency of errors and any of the experimental variables. Presumably, by adulthood such basic spatial relationships as above-below and right-left are so overlearned that only differences in speed of processing would remain as the measure of processing strategies. Yet, in real life, adults sometimes do make mistakes in carrying out spatial instructions. They do sometimes turn right when told to turn left, particularly, it seems, when forced to react quickly. Would rapid pacing of instructions, therefore, force errors that would be patterned in ways consistent with reaction time differences in studies with adults and with error patterns in studies with children? This question suggested the following experimental design.

\section{METHOD}

\section{Subjects}

The subjects were 148 undergraduate women tested in groups of 15 to 25 .

\section{Procedure}

Each subject was given a booklet consisting of three $8^{1 / 2} \times 11$ in. sheets of paper. On each sheet, eight 1 -in. squares were printed. The experimenter read the following instructions: "I'd like to see how quickly and accurately people can draw one object in spatial relation to another object. Each of you has a booklet with 24 squares, eight squares per page. Notice how the squares are numbered on each page-down the page rather than across, with the numbers 1 through 8 repeated on each page. I will ask you to draw, as quickly as you can, a small circle in relation to the square. For each of the 24 drawings, 1 first will say the number of the square, and then what spatial relation between the circle and the square should be represented. As soon as I say what the reiation should be, draw the circle. If you are unable to draw the circle in the time allotted, don't worry. Just skip it and keep pace with me. Don't try to correct if you think you made a mistake. Just keep pace. The pace will be fast-about like this: $1 \ldots 2 \ldots 3 \ldots 4 \ldots$ After number 8 , turn the page and we will 
go on to the next eight."

The pace given in the example was one square approximately every $2 \frac{1 / 2}{2}$ seconds, or just enough time for the spatial relation to be described (in four words consisting of five syllables) plus a brief pause. The subjects were told to poise their pencils just above the first square and to wait for the first instruction.

Experimental variables. The variables represented in the commands were: spatial dimension (vertical, horizontal), spatial direction (above-below, right of/left of), and, finally, grammatical form of the instruction. The commands were phrased so that what in Huttenlocher's design would be the mobile element (the circle to be drawn) was either the logical subject (e.g., "circle above square") or the object of action (e.g., "square below circle"). All combinations of these variables yielded eight discrete commands, shown in Table 1. This total set of eight spatial relations comprised one eight-trial set. Three such sets were read, one for each of the 3 pages in the subjects' booklets, for a total of 24 trials. Within each set of eight, the statements were so ordered that the same spatial direction and grammatical form of the instruction never occurred more than once in succession. Different orderings of the three sets of eight trials were used from one group of subjects to another.

\section{RESULTS AND DISCUSSION}

The mean numbers of total errors per trial as a function of experimental condition are shown in Figure 1. The mean numbers of errors per trial are plotted along the vertical axis. A mean score of, say, .36 indicates that the subjects made an error on average more than one-third of the time. Each data point represents the mean score, for the 148 subjects, for the three instances of each of the eight statements (i.e., eight combinations of the variables grammatical form by dimension by direction). Thus, each data point represents the mean of $148 \times 3=444$ scores.

An analysis of variance for repeated measures on the total number of errors disclosed significant main effects of grammatical form $(\mathrm{F}=35.3$, $\mathrm{df}=1 / 147)$, direction $(\mathrm{F}=14.4, \mathrm{df}=1 / 147), \quad$ and dimension $(\mathrm{F}=88.5$, $\mathrm{df}=1 / 147$ ), (all ps $<.0005)^{2}{ }^{2}$ Within each of the four direction statements, performance was better when the circle was the logical subject than when it was the logical object of action. Within each of the grammatical form conditions, performance was better on the above statements than on the below statements and was better on the right-of than on the left-of statements. Across the direction and grammatical form conditions, the horizontal dimension (right plus left) was

Table 1

Eight Instructional Phrases Used

\begin{tabular}{lll}
\hline & \multicolumn{1}{c}{$\begin{array}{c}\text { Circle as } \\
\text { Logical Subject }\end{array}$} & $\begin{array}{c}\text { Circle as } \\
\text { Logical Object }\end{array}$ \\
\hline $\begin{array}{l}\text { Vertical } \\
\text { Spatial } \\
\text { Dimension }\end{array}$ & $\begin{array}{l}\text { Circle above square } \\
\text { Circle below square }\end{array}$ & $\begin{array}{l}\text { Square above circle } \\
\text { Square below circle }\end{array}$ \\
$\begin{array}{l}\text { Horizontal } \\
\text { Spatial } \\
\text { Dimension }\end{array}$ & $\begin{array}{l}\text { Circle right of square } \\
\text { Circle left of square }\end{array}$ & $\begin{array}{l}\text { Square right of circle } \\
\text { Square left of circle }\end{array}$ \\
\hline
\end{tabular}

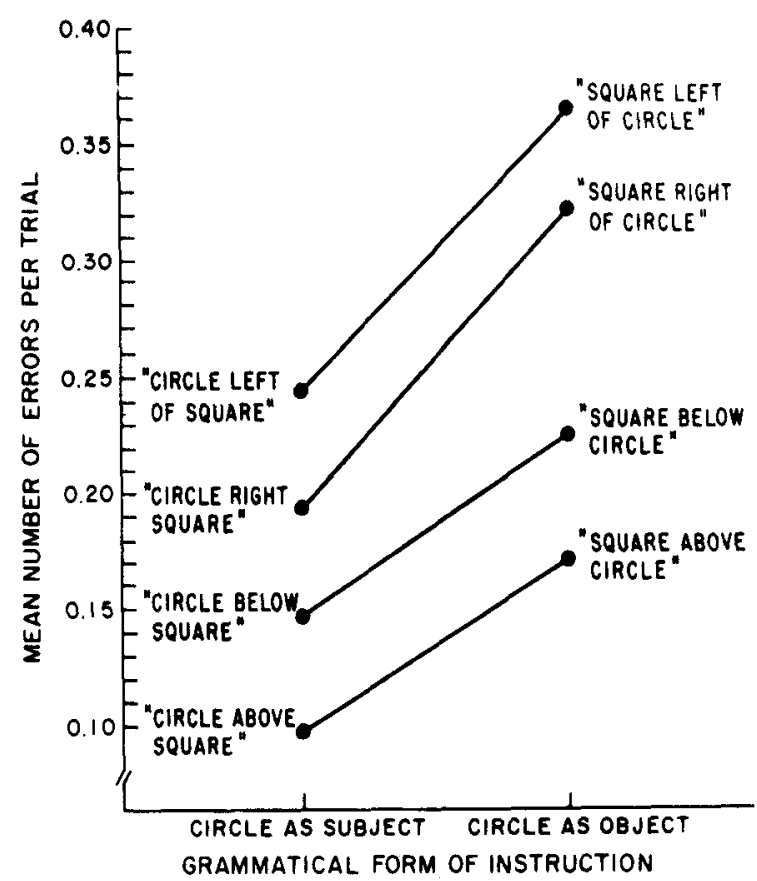

Figure 1. Mean number of errors per trial for each of the eight spatial instructions. Each data point represents the mean score, for the 148 subjects, for the three instances of each of the eight instructions (i.e., eight combinations of the variables grammatical form by dimension by direction). Each data point therefore represents the mean of 444 scores.

substantially more difficult than the vertical dimension (above plus below).

Finally, Figure 1 illustrates a modest but statistically significant interaction between dimension and grammatical form $(\mathrm{F}=4.78, \mathrm{df}=1 / 147, \mathrm{p}=.030)$. Though the horizontal dimension was more difficult than the vertical dimension in both grammatical form conditions, judging from the differences in slopes it appears as though the difficulty has been accentuated when the circle was the logical object, suggesting that the combined effects of grammatical form and dimension are not simply additive.

The remaining interactions (Grammatical Form by Direction, Dimension by Direction, Grammatical Form by Dimension by Direction) were all nonsignificant (all Fs $<1.0$ ).

These error scores, therefore, seem to be consistent with previous findings. The statements in which the circle is the logical object do appear to be more difficult to understand than the statements in which the circle is the logical subject, and the directions left of and below do appear to be harder to follow than their opposites-right of and above.

\section{Individual Differences}

More than a fourth of the subjects did very well on the task, making three or fewer errors in 24 trials. 
Almost one-sixth of the subjects did very badly, making from 10 to 15 errors. Were all the subjects affected similarly by the experimental variables?

Table 2 shows the relation between the subjects' overall accuracy and the proportional distribution of those errors the subjects did make, in each grammatical form, dimension, and direction condition. Reading down the left-hand column, the 148 subjects are distributed in five subgroups according to the number of total errors they made, from few ( 1 to 3 ) to many (13-15). Each of the five subgroups made proportionately more of their errors on commands with the circle as logical object than on commands with the circle as logical subject, and by roughly equal margins. Each subgroup also made proportionately more errors on the horizontal dimension than on the vertical dimension, though here the horizontal dimension appears to have been relatively less difficult for the subjects who made 10 or more errors. Generally, though, all the subjects, irrespective of their overall accuracy, seem to have been affected in substantially similar ways by the grammatical form and dimension conditions.

Let us now, however, compare performance on unmarked directions-above and right-with performance on marked directions-below and left. Of those subjects who made fewer total errors, a substantially greater proportion of their errors occurred on the marked terms. But among the subjects who made more total errors, this asymmetry is weaker and, in some cases, is eliminated. Thus, among the 45 subjects who made only one to three errors out of 24 trials, $61.7 \%$ of the errors were on the marked terms, $38 \%$ on the unmarked terms. But of the 24 subjects who made as many as 10 to 15 errors (the bottom two subgroups in the table), the split was 50-50. The marking effect found in the current study therefore appears to have been due predominantly to those subjects who did better on the task.
This finding is difficult to explain. It is generally accepted that the syntactic features of sentences, that is, the way the sentence is structured (here referred to as grammatical form), are processed before the semantic features (right-left, above-below) are processed. If so, perhaps the subjects who made many errors simply were not getting past the first-level, or syntactic, analysis stage.

Performance of left-handers. Having found these individual differences, one is led to wonder about another possible source of differences. Sixteen of the 148 subjects were left-handed. Insofar as the left hand, for the left-hander, is the normative hand, would left act for them like the unmarked direction in space and right like the marked direction?

Figure 2 illustrates, for the 16 left-handers, the mean number of errors per trial for each of the eight spatial commands. Like the entire sample of 148 subjects shown in Figure 2, the left-handers do worse on commands with the circle as logical object and worse on the horizontal dimension. And they do worse on below than on above. But they do better on left than on right, just the reverse of the whole sample of 148 . So handedness may be a critical and theoretically interesting variable in spatial-processing tasks, a possibility that neuropsychologists like Hécaen (Hécaen \& de Ajuriaguerra, 1964), Zangwill (1960), and Benton (1959) have long recognized. ${ }^{3}$

\section{Dimension Effect}

Finally, let us consider the signficiant dimension effect: As far as can be told, neither considerations about grammatical form nor about lexical marking seem to explicitly predict the differences found here between the spatial dimensions horizontal and vertical. That errors were significantly more frequent on the horizontal dimension should not surprise. In normal development, right-left discrimination lags far behind other spatial

Table 2

Proportional Distribution of Subjects' Total Errors in Each Grammatical Form (Circle as Subject, Circle as Object), Dimension (Vertical, Horizontal), and Direction (Unmarked, Marked) Condition as a Function of Overall Performance

\begin{tabular}{|c|c|c|c|c|c|c|c|c|c|c|}
\hline \multirow{3}{*}{$\begin{array}{c}\text { Total No. } \\
\text { of Errors } \\
\text { in } 24 \\
\text { Trials } \\
\end{array}$} & \multirow{3}{*}{$\begin{array}{c}\text { Mean } \\
\text { Percentage } \\
\text { of Errors }\end{array}$} & \multirow{3}{*}{$\begin{array}{c}\mathrm{N} \text { of } \\
\text { Subjects }\end{array}$} & \multicolumn{8}{|c|}{ Percentage of Total Number of Errors } \\
\hline & & & Circle as & Circle as & Ver- & Hori- & Unn & ked & $\mathrm{Ma}$ & \\
\hline & & & Subject & Object & tical & zontal & Above & Right & Below & Left \\
\hline $1-3$ & 7.5 & 45 & 39.5 & 60.5 & 34.6 & 65.4 & 11.1 & 27.2 & 23.5 & 38.3 \\
\hline $4-6$ & 20.8 & 37 & 42.7 & 57.3 & 34.1 & 65.9 & $\begin{array}{r}11.4 \\
\Sigma\end{array}$ & $\begin{array}{l}24.9 \\
6.2\end{array}$ & $\begin{array}{r}22.7 \\
\Sigma\end{array}$ & $\begin{array}{l}41.1 \\
3.8\end{array}$ \\
\hline $7-9$ & 32.3 & 33 & 39.1 & 60.9 & 35.5 & 64.5 & $\begin{array}{r}16.8 \\
\Sigma\end{array}$ & $\begin{array}{l}32.0 \\
8.8\end{array}$ & $\begin{array}{r}18.8 \\
\Sigma\end{array}$ & $\begin{array}{l}32.4 \\
1.2\end{array}$ \\
\hline $10-12$ & 45.6 & 18 & 34.5 & 65.5 & 42.1 & 57.9 & $\begin{array}{r}19.8 \\
\Sigma\end{array}$ & $\begin{array}{l}27.4 \\
7.2\end{array}$ & $\begin{array}{r}22.3 \\
\Sigma\end{array}=$ & $\begin{array}{l}30.5 \\
2.8\end{array}$ \\
\hline $13-15$ & 59.0 & 6 & 37.6 & 62.4 & 41.2 & 58.8 & $\begin{array}{r}20.0 \\
\Sigma\end{array}$ & $\begin{array}{l}30.6 \\
0.6\end{array}$ & $\begin{array}{r}21.2 \\
\Sigma\end{array}$ & $\begin{array}{l}28.2 \\
9.4\end{array}$ \\
\hline
\end{tabular}




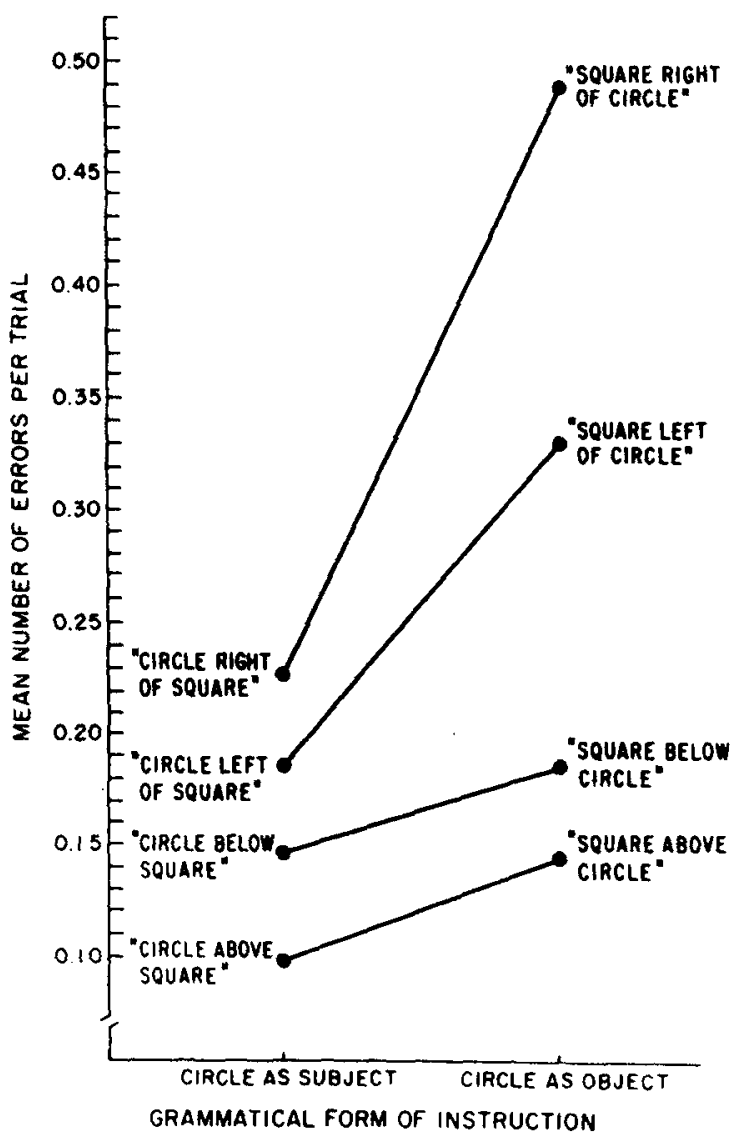

Figure 2. Left-handers $(n=16)$ : Mean number of errors per trial for each of the eight spatial instructions. Each data point represents the mean score, for the 16 left-handed subjects, for the three instances of each of the eight instructions. Each data point represents the mean of 48 scores.

concepts such as up-down and front-back. Benton (1959), for instance, reported that the average child masters the distinction between up and down in his preschool years but does not begin to make the right-left distinction until his early elementary years, A similar lag exists between right-left and both front-back and up-down (Harris, 1972). Many variables could contribute to this lag. Some could be termed "environmental" variables, e.g., there are up-down cues but not right-left cues in objects themselves-what Howard and Templeton (1966) call "intrinsic axes"-that work in behalf of up-down discrimination. There is greater opportunity to practice up and down; and up.down orientation has far greater operational significance than does right-left orientation.

Other variables are more obviously "structural" or biological. For instance, Rudel and Teuber (1963), like Sutherland (1957), suggested that human beings might possess an innate neurological classifying system that might be more geared for up-down than for right-left discrimination. And Tschirgi (1958) and Corballis and Beale (1970) suggested that right-left confusion might be a necessary consequence of man's bilateral symmetry (thus, mirror images can be discriminated at all only because man is not completely bilaterally symmetrical but has evolved certain asymmetric features, most crucially, functional and structural asymmetry of the two hemispheres of the brain). The present findings suggest that, under appropriate conditions, the relatively weaker right-left discrimination in adults can easily be brought out.

\section{REFERENCES}

Benton, A. L. Right-left discrimination and finger localization. New York: Hoeber-Harper, 1969.

Corballis, M., \& Beale, I. Bilateral symmetry and behavior. Psychological Review, 1970, 77, 451-464.

Clark, H. H., \& Chase, W. G. On the process of comparing sentences against pictures. Cognitive Psychology, 1972,3, 472-517.

Harris, L. J. Discrimination of left and right and development of the logic of relations. Merrill-Palmer Quarterly of Behavior and Development, 1972, 18, 307-320.

Hécaen, H.. \& de Ajuriaguerra, J. Left-Handedness: Manual superiority and cerebral dominance. New York: Grune \& Stratton, 1964.

Howard, I., \& Templeton, W. Human Spatial Orientation. London: Wiley, 1966.

Huttenlocher, J., \& Strauss, S. Comprehension and a statement's relation to the situation it describes. Journal of Verbal Learuing and Verbal Behavior, 1968, 7, 527-530.

Olson, G. M., \& Laxar, K. Asymmetries in processing the terms "right" and "left." Journal of Experimental Psychology, $1973,100,284-290$.

Olson, G. M.. \& Laxar, K. Processing the terms "right" and "left": A note on left-handers. Joumal of Experimental Psychology, 1974, 102, 1135-1137.

Rubel, R., \& Teuber, H. L. Discrimination of direction of line in children. Journal of Comparative and Physiological Psychology, 1963, 56. 892-898.

Sutherland, $N$. Visual discrimination of orientation and shape by the octopus. Nature, 1957, 179, 11-13.

Tschirgi, R. Spatial perception and central nervous system symmetry. Arquivos de Neuropsiquiatria, 1958, 16, 364-366. Cited by A. Scheibel, and M. Scheibel, in V. Mountcastle, (Ed.), Interhemispheric relations and cerebral dominance. Baltimore: Johns Hopkins, 1962. Pp. 29-30.

Werner, H. Comparative psychology of mental development. (Rev. Ed.) New York: Science Editions, 1961.

Zangwill, $O$. W. Cerebral dominance and its relation to psychological function. London: Oliver \& Boyd, 1960.

\section{NOTES}

1. One piece of evidence is in language. Most every language has terms expressing spatial relationships that either stand for, or refer directly to, parts of the body. For example, the Mande (African) group of languages expresses "behind" by the term "the back"; the word "before" is the same as the word for "eye": "on" is the same as "neck": "in" is the same as "stomach," and so forth. Werner calls these body words "anthropomorphic substantives." Such anthropomorphic substantives can be found in English too. Two outstanding examples are the terms "in back" and "face," which simultaneously designate a part of the body and a spatial relation.

2. Three separate analyses were actually carried out: on errors of commission (misplacements of the circle in relation to the square), errors of omission (failure to draw the circle), and total errors (omission plus commission). Total errors are reported here, since the results of the analyses of omission and of commission errors were very similar.

3. Olson and Laxar (1974), however, falled to find such an asymmetry in a reaction time experiment with 16 left-handers. Their subjects saw four different displays, containing either the word "right" or "left" centered in a small square, and a black dot located either to the left or right of the square. The subjects were to decide as quickly as possible whether the word correctly named the side on which the dot appeared. Previously, Olson and Laxar (1973) found that right-handers responded significantly more quickly to the "right" direction. The absence of asymmetrical processing for the left-handers led Olson and Laxar (1974) to suggest either that an underlying conceptual 
asymmetry was absent for the left-handers or that the effects of the asymmetry had been cancelled as the result of a conflict between alternative sets of representations, one set based on handedness in which the left direction becomes the reference direction, the other set based on the fact that left-handers live in an essentially right-handed world and so might be expected to share the right-hander's internal model of space. As Olson and Laxar (1974) point out, their findings do not permit them to choose between the two possible interpretations. But at least so far as the current findings are concerned, an underlying conceptual asymmetry in left-handers just the reverse of the right-handers appears to be indicated.

(Received for publication July 14, 1974 accepted September 9, 1974.) 